Original Article

\title{
An alternative intervention for urinary incontinence: Retraining diaphragmatic, deep abdominal and pelvic floor muscle coordinated function
}

\author{
Hsiu-Chuan Hung ${ }^{a}$, Sheng-Mou Hsiao ${ }^{b}$, Shu-Yun Chih ${ }^{\text {a,c }}$, Ho-Hsiung Lin ${ }^{\text {d }}$, Jau-Yih Tsauo ${ }^{\text {a,c,* }}$

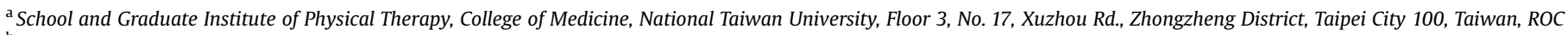 \\ ${ }^{\mathrm{b}}$ Department of Obstetrics and Gynecology, Far Eastern Memorial Hospital, Pan-Chiao, Taipei, Taiwan \\ ${ }^{c}$ Physical Therapy Center, National Taiwan University Hospital, Taipei, Taiwan \\ ${ }^{\mathrm{d}}$ Department of Obstetrics and Gynecology, College of Medicine, National Taiwan University and the Hospital, Taipei, Taiwan
}

\section{A R T I C L E I N F O}

\section{Article history:}

Received 28 August 2009

Received in revised form

13 January 2010

Accepted 21 January 2010

\section{Keywords:}

Pelvic floor muscles

Randomized controlled trial

Urinary incontinence

Transversus abdominis

\begin{abstract}
A B S T R A C T
This study was a randomized controlled trial to investigate the effect of treating women with stress or mixed urinary incontinence (SUI or MUI) by diaphragmatic, deep abdominal and pelvic floor muscle (PFM) retraining. Seventy women were randomly allocated to the training $(n=35)$ or control group $(n=35)$. Women in the training group received 8 individual clinical visits and followed a specific exercise program. Women in the control group performed self-monitored PFM exercises at home. The primary outcome measure was self-reported improvement. Secondary outcome measures were 20-min pad test, 3-day voiding diary, maximal vaginal squeeze pressure, holding time and quality of life. After a 4-month intervention period, more participants in the training group reported that they were cured or improved $(p<0.01)$. The cure/improved rate was above 90\%. Both amount of leakage and number of leaks were significantly lower in the training group $(p<0.05)$ but not in the control group. More aspects of quality of life improved significantly in the training group than in the control group. Maximal vaginal squeeze pressure, however, decreased slightly in both groups. Coordinated retraining diaphragmatic, deep abdominal and PFM function could improve symptoms and quality of life. It may be an alternative management for women with SUI or MUI.
\end{abstract}

(c) 2010 Elsevier Ltd. All rights reserved.

\section{Introduction}

Stress urinary incontinence (SUI) has been defined by the International Continence Society as "the complaint of involuntary leakage on effort or exertion, or on sneezing or coughing" (Abrams et al., 2002). Pelvic floor muscle training (PFMT) has been widely used to treat SUI since Kegel (1948) introduced this kind of exercise, and its effectiveness has been proven in numerous randomized controlled trials (Hay-Smith and Dumoulin, 2006).

Recent studies have focused on the relationship of pelvic floor muscles (PFM) and abdominal muscles (Sapsford and Hodges, 2001; Sapsford et al., 2001; Neumann and Gill, 2002; Madill and McLean, 2006). Sapsford and Hodges (2001), Sapsford et al. (2001) found that the co-contraction of PFM and deep abdominal muscles occurred during both PFM voluntary contraction and abdominal maneuvers.

\footnotetext{
* Corresponding author. School and Graduate Institute of Physical Therapy, College of Medicine, National Taiwan University, Floor 3, No. 17, Xuzhou Rd., Zhongzheng District, Taipei City 100, Taiwan, ROC. Tel.: +886 2 33668130; fax: +886233668161.

E-mail address: jytsauo@ntu.edu.tw (J.-Y. Tsauo).
}

Indeed, one cannot contract the PFM even moderately without also contracting the deep abdominal muscles (Neumann and Gill, 2002). Madill and McLean (2006) found that deep abdominal muscle contraction increased intra-vaginal pressure. Moreover, Thompson et al. (2006) found abdominal muscles were more active than PFM in symptomatic women, and suggested careful monitoring of this phenomenon when teaching PFM contractions. Together, these results suggest that a coordinated approach of both PFM and deep abdominal muscles may be beneficial for women with SUI.

Sapsford (2004) proposed a treatment approach by motor relearning of diaphragmatic, deep abdominal and PFM. This new approach emphasizes the coordination of diaphragm, deep abdominal muscles and PFM rather than muscle strengthening independently. This exercise program could be taught by observation and chest and abdominal palpation, obviating the need for vaginal palpation which may deter women in Taiwan from PFMT.

So far, only one randomized control trial has addressed the effect of abdominal muscle training on SUI. The results showed that additional training of the Transversus abdominis (TrA) after PFMT and neuromuscular stimulation did not provide incremental improvement of SUI (Dumoulin et al., 2004). However, the coactivation and coordination of the TrA and PFM was not the target 
in Dumoulin's work. Hence, the purpose of the present study was to investigate the effect of treating SUI symptoms in women by retraining diaphragmatic, deep abdominal and PFM coordinated function.

\section{Methods}

\subsection{Design}

This was a single-blind, randomized controlled trial. All participants received a 4-month intervention period according to group allocation after the first evaluation, and received a second evaluation after the intervention period.

\subsection{Setting and participants}

The study was conducted at a Women's Health Laboratory. The local ethics committee approved the study. Female volunteers were recruited through a newspaper advertisement. Women were eligible for this trial if they were aged 18-65 years and had at least one episode of SUI symptom during the previous month. Two standardized questions about urinary incontinence (UI) used to determine the eligibility. The first question was for SUI and the second was for urge UI. The sensitivity/specificity was $0.85 / 0.91$ and $0.90 / 0.90$ for the first and second question respectively (Rohr et al., 2004). Women who answered "yes" to the first question only and who answered "yes" to both questions were categorized as SUI and mixed UI (MUI), respectively and recruited. Women who answered "yes" to the second question only were categorized as urge UI and excluded (Rohr et al., 2004).

Exclusion criteria included being pregnant or less than three months postpartum, having systemic neuromuscular disease, having had previous surgery or intensive PFMT for UI, having severe low back pain or pelvic pain, undergoing concurrent treatment for UI or low back pain, having had a radical hysterectomy or having ongoing urinary tract infections.

\subsection{Randomization}

A total of 239 potential participants were screened via telephone interview and 80 provided written informed consent before the first evaluation (Fig. 1). Participants were not charged for the examination or intervention. They were randomly allocated to training group or control group. Block randomization with a maximum of 6 was used. Each participant chose and opened one opaque, sealed envelope by herself. All were asked not to reveal their group allocation to the evaluators. Only the participant herself and the physical therapist involved in training $(\mathrm{H}-\mathrm{CH})$ knew the group allocation.

\subsection{Intervention}

Participants in both groups were individually taught anatomy of the pelvic floor, lower urinary tract and continence mechanism

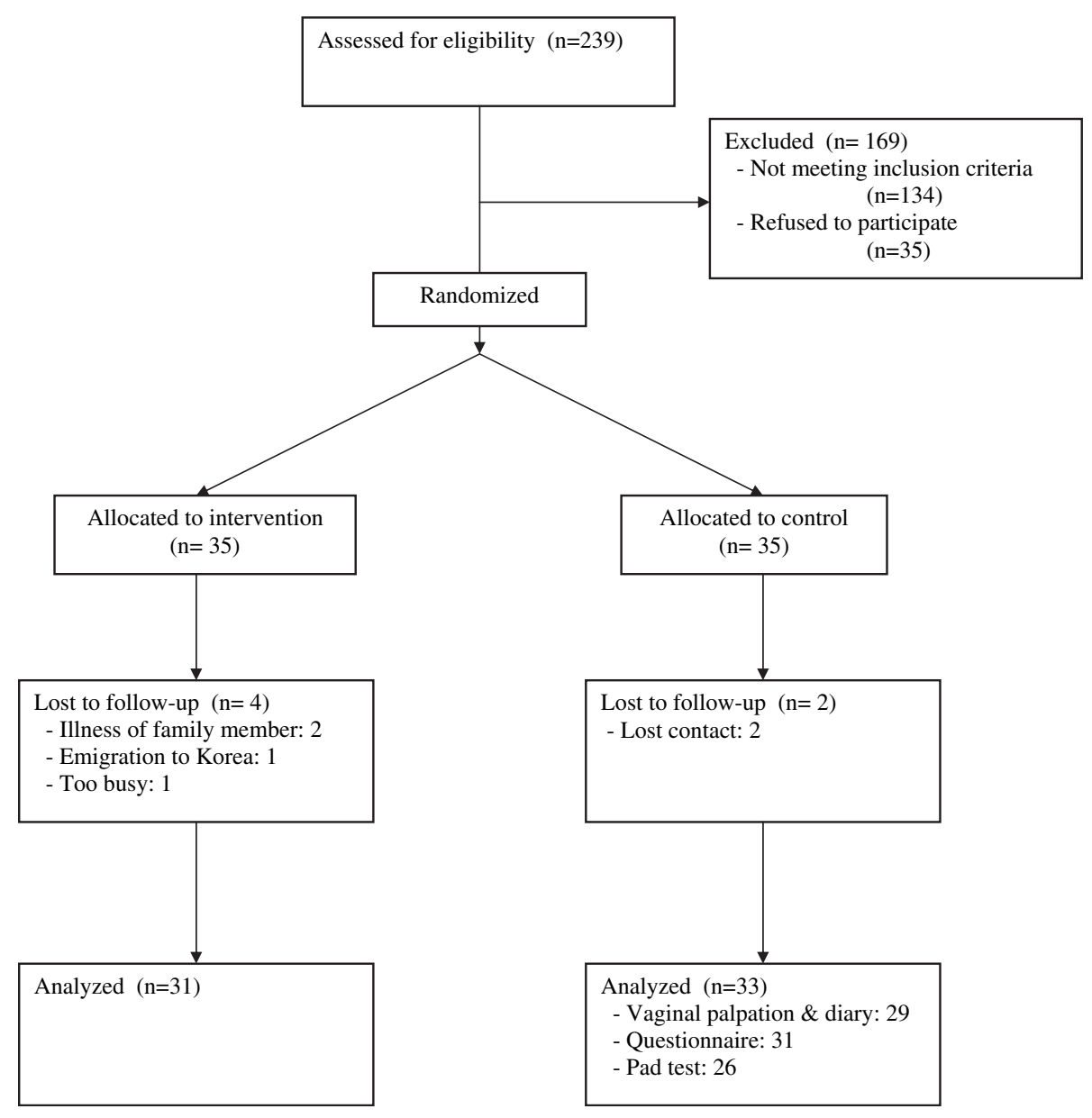

Fig. 1. Trial profiles of participants in each stage. 
during the first evaluation by an experienced physical therapist (S-YC) with three years' clinical experience in treating female UI. Vaginal palpation was applied for the valid evaluation of vaginal squeeze pressure and the evaluator instructed women how to contract the PFM correctly.

The exercise regimen for the training group followed Sapsford's (2004) design. The five stages included 1) diaphragmatic breathing; 2) tonic activation of TrA and PFM; 3) muscle strengthening of TrA, PFM, and internal obliques; 4) functional expiratory patterns like coughing and sneezing; and 5) impact activities such as running and jumping. Participants in the training group met the training physical therapist twice a month for 4 months for monitoring of exercise progression, moving to the next stage when appropriate. To avoid contamination of exercise effect, participants were asked not to perform the "isolated" PFM voluntary contraction exercise during the intervention period. The Appendix provides a detailed exercise regimen and progression, including the prerequisites, exercise position, instruction, feedback, and home exercise prescribed for each stage. The pre-requisite determined the progression to the next stage.

Participants in the control group received oral instructions and usual information, consisting of introduction for urinary incontinence, PFM exercise, and bladder hygiene. For ethical considerations, they were given the option of receiving the same program as the training group after the trial.

\subsection{Outcomes}

The primary outcome measure was self-reported improvement. At the second evaluation (after four months), self-reported improvement on a 4-point Likert scale (worse, unchanged, improved, cured) was recorded (O'Brien et al., 1991; Lagro-Janssen et al., 1992; Arvonen et al., 2001). Other assessments performed at both first and second evaluations consisted of a 20-min pad test with standardized bladder volume (Sand, 1992; Wu et al., 2006), a 3-day voiding diary (Groutz et al., 2000), PFM function and quality of life. All measures, except the 20 -min pad test, were administered by the same blinded evaluator (S-YC).

A female technician blinded to participants' allocation administered the 20-min pad test (Sand, 1992; Wu et al., 2006). After infusion of $250 \mathrm{~mL}$ distilled water into the bladder and a preweighted perineal pad inserted inside the underwear, each participant was asked to do each of the following 10 times: cough, valsalva, deep knee bends, jump up and down in place and walk up and down five stairs. Sensitivity for this test was shown to be better than the 1-h pad test for SUI in a previous study in the same setting in Taiwan (Wu et al., 2006).

Participants used a 3-day voiding diary at home. They were asked to record every event of voiding, urgency and urinary leak, and describe the amount of leakage. The mean number of voiding and leaks per day were calculated for analysis. The test-retest reliability of this method has been established for voiding and leakage episodes (concordance correlation coefficient 0.83 and 0.86 , respectively) (Groutz et al., 2000). The diary was used as an outcome measure only; recording during the intervention period was not encouraged in either group.

Maximal vaginal squeeze pressure and holding time were measured simultaneously by a manometer ${ }^{1}$ with the participant lying in a bent-knee position to represent PFM strength and endurance. The test-retest reliability of squeeze pressure recording in this position was good (ICC $=0.95$ ) (Frawley et al., 2006) Participants were asked to contract PFM maximally and hold until being instructed to relax for three repetitions. Evaluator's hand

\footnotetext{
${ }^{1}$ Peritron 9300 perineometer, Cardio-Design, Perth, Australia.
}

palpation and visual observation was used to restrict activity of the abdominal and hip muscles. The last two contractions were recorded and averaged for analysis.

The impact of incontinence on health-related quality of life was assessed by the Symptom Impact Index (Black et al., 1996), Chinese version (Chen et al., 2003). A previous pilot study in Taiwan showed good test-retest reliability ( $r=0.87-0.91)$ (Chen et al., 2003).

Adverse events during the intervention period were recorded. Training group adherence to the protocol was recorded as attendance at the training session.

\subsection{Sample size estimation}

Since no publication using the same approach was available, the estimated sample size was based on a previous randomized controlled trial of the effect of PFMT (Wilson et al., 1987). Using the same outcome variable (number of leaks in a 3-day diary), sample size was set at 30 subjects per group to provide a power of $80 \%$ and an $\alpha$ of $5 \%$ to detect the difference between groups, assuming a median to large effect size.

\subsection{Statistical analysis}

To compare basic characteristics and outcome variables at baseline, differences in age, BMI, maximal vagina squeeze pressure and holding time between groups was tested by Independent $t$-test. Mann-Whitney $U$-test was used to determine the difference of parity, duration of symptoms, leakage amount, voiding frequency, leakage frequency, and quality of life items between groups because the variables were not normally distributed. The proportion of participants with related symptoms was compared by ChiSquare Statistic.

To assess the treatment effect between groups, the proportion of participants reported cured/improved in each group was compared using Chi-Square statistics. Two-way mixed ANOVA (group $\times$ time) was used to detect the different treatment effect between groups for vaginal squeeze pressure and holding time because they were normally distributed. The Mann-Whitney $U$-test was used to compare groups for ordinal variables and other continuous variables not normally distributed. If there was no difference between groups, the Wilcoxon Signed-Ranks Test was used to detect possible change within each group. Two-tailed $p$ value $<0.05$ was considered significant. Statistical analysis was completed using SPSS for Windows, version 11.0 (SPSS Inc., Chicago, IL).

\section{Results}

Four participants in the training group and two in the control group dropped out (Fig. 1) for a dropout rate of $8.6 \%$. For the initial 70 participants with the 64 who participated in the second evaluation, the demographic data and all outcome variables at first evaluation were similar. Both the data from participants completing the second evaluation $(n=64)$ and the data from all participants based on the intention to treat basis were analyzed to assess treatment effect. In the latter condition, all missing values were carried forward by their baseline values, and self-reported improvement was given as unchanged. The results did not differ whether we used the data from all 70 participants or the completed data that excluded missing data for analysis. Therefore, we reported data of the 64 participants who completed the study.

The basic characteristics and related symptoms of the two groups were comparable at baseline except for the number of women with urgency (Table 1 ). In addition, there was no difference between groups in any outcome variable at first evaluation (Tables 2-4). 
Table 1

Basic characteristics and self-reported symptoms at baseline.

\begin{tabular}{|c|c|c|c|c|c|}
\hline & \multicolumn{2}{|c|}{$\begin{array}{l}\text { Training group } \\
(n=31)\end{array}$} & \multicolumn{2}{|c|}{$\begin{array}{l}\text { Control group } \\
(n=33)\end{array}$} & \multirow[t]{2}{*}{$p$ Value } \\
\hline & Mean & SD & Mean & SD & \\
\hline Age $(y)^{\mathrm{a}}$ & 48.6 & 6.4 & 48.9 & 6.4 & 0.874 \\
\hline Body mass index $\left(\mathrm{kg} / \mathrm{m}^{2}\right)^{\mathrm{a}}$ & 22.4 & 2.3 & 22.0 & 2.4 & 0.676 \\
\hline Parity ${ }^{\mathrm{b}}$ & 3 & 1.3 & 3.1 & 1.6 & 0.726 \\
\hline \multirow[t]{2}{*}{ Duration of symptoms $(\mathrm{mo})^{\mathrm{b}}$} & 104.5 & 89.7 & 98.9 & 71.2 & 0.840 \\
\hline & $n$ & $(\%)$ & $n$ & $(\%)$ & \\
\hline Low back pain ${ }^{c}$ & $\overline{11}$ & $(35.5)$ & 12 & $\overline{(36.4)}$ & 0.942 \\
\hline Postmenopausal $^{\mathrm{c}}$ & 15 & $(48.4)$ & 13 & $(39.4)$ & 0.235 \\
\hline Unawareness incontinence $^{c}$ & 7 & $(22.6)$ & 6 & $(18.2)$ & 0.662 \\
\hline Urge incontinence $\mathrm{c}^{\mathrm{c}}$ & 21 & (67.7) & 15 & $(45.5)$ & 0.072 \\
\hline Urgency $^{c}$ & 15 & $(48.4)$ & 7 & $(21.2)$ & $0.022^{*}$ \\
\hline Frequency ${ }^{c}$ & 14 & $(45.2)$ & 18 & (54.5) & 0.453 \\
\hline Nocturia $^{c}$ & 7 & (22.6) & 12 & (36.4) & 0.228 \\
\hline
\end{tabular}

*Statistically significant $(p<0.05)$.

a Independent $t$-Test.

b Mann-Whitney $U$-Test.

c Chi-Square Statistic.

Significantly more participants in the training group reported cured or improved symptoms than in the control group (96.7\% vs. $66.6 \%, p=0.002$ ) (Table 5).

As shown in Table 2, there was no significant difference between groups after intervention in either amount $(p=0.346)$ or number of leaks ( $p=0.473$ ). However, the training group showed significant improvement in amount of leakage during the pad test $(p=0.006)$, while the control group did not $(p=0.233)$. While participants in both groups significantly reduced total voiding frequency per day, only those in the training group significantly reduced number of leaks per day $(p=0.042)$.

Changes in maximal pressure and holding time are shown in Table 3. There was no statistically significant interaction effect (group $\times$ time) either on maximal vaginal pressure $(F=0.347$, $p=0.558)$ or holding time $(F=0.404, p=0.527)$. Both maximal vaginal pressure and holding time, however, showed a significant main effect for time. Maximal vaginal squeeze pressure significantly decreased $\left(34.3 \pm 2.5\right.$ to $\left.31.3 \pm 2.3 \mathrm{~cm} \mathrm{H}_{2} \mathrm{O}, F=7.58, p=0.008\right)$ and holding time significantly increased $(8.1 \pm 0.6$ to $11.2 \pm 0.8 \mathrm{~s}$, $F=25.54, p<0.001$ ) after 4 -month intervention period.

The Symptom Impact Index indicated only two significant differences between groups after intervention (Tables 4). Within group analysis showed a significant reduced number of worries in both groups (training $p<0.001$; control $p=0.002$ ), but number of activities affected was significantly reduced only in the training group (training $p<0.001$; control $p=0.104$ ). Similarly, avoiding activities due to worrying about leaking was significantly improved in both groups (training $p<0.001$; control $p=0.002$ ), but avoiding activity due to needing a toilet was significantly improved only in the training group (training $p<0.001$; control $p=0.085$ ).
No side effect or adverse event was reported by any participant. According to the intervention notes, some participants in the training group reported good response of tonic activation of $\operatorname{Tr} A$ to inhibit urgency and urge incontinence.

Twenty-six patients (84\%) in the training group participated in 8 individual visits; the other patients (16\%) participated in only 7 visits due to business or travel schedule.

\section{Discussion}

The present study demonstrated that a 4-month period intervention utilizing trunk muscle synergies could improve the symptoms and quality of life for women with SUI or mixed UI (MUI). The cured/improved rate was $96.7 \%$ in the training group and $66.6 \%$ in the control group. The number of leaks per day recorded in a 3-day voiding diary was significantly reduced in the training group but not in the control group, and more improvement in quality of life was reported in the training group than in the control group.

The treatment effect of this new approach seemed to be similar to that of PFMT when compared with previous studies. The cured/ improved rate of the training group in the present study (above $90 \%$ ) was higher than those of some previous studies (58-74\%) (Wilson et al., 1987; O’Brien et al., 1991; Lagro-Janssen et al., 1992; Arvonen et al., 2001) and similar to others (92-96\%) (Bo et al., 1990, 1999). The cured/improved rate of the present study was also better than PFM exercise combined with electrical stimulation (61\%) in a clinical trial in Taiwan (Chen et al., 1999). Heterogeneity of factors (e.g., incontinence type, exercise intensity, duration of intervention, participant's adherence, and measurement tool) makes comparison of studies problematic.

The treatment effect in the training group may be the result of functional training. Participants learned to coordinate their diaphragm, PFM, TrA, and even obliquus internus abdominis, to enhance an efficient forced expiratory pattern, which was the primary situation in which SUI occurred. The correct diaphragm breathing pattern is an essential part of successful forced expiration without leakage, as described by Sapsford (2004). This approach emphasizes the coordination of these muscles to maintain the stress continence mechanism, unlike previous approaches which focused on strengthening a specific muscle. Previous studies have linked normal PFM function not only to strength, but also to endurance, speed of contraction, and muscle stiffness (Howard et al., 2000; Morin et al., 2004; Morkved et al., 2004). However, we made no direct measure of any of these variables. We surmise an improvement in muscle function, but have yet to test whether motor learning was the mechanism involved.

The high improvement rate in the control group in this study (66.6\%) may explain the lack of significant difference for some variables (amount of leakage, number of leaks and two aspects of

Table 2

Median (25th-75th percentile) of amount of leakage during pad test, number of voids and leaks during 3-day diary.

\begin{tabular}{|c|c|c|c|c|c|c|c|c|c|c|c|}
\hline \multirow[b]{3}{*}{ Amount of leakage $(g)^{\mathrm{c}}$} & \multicolumn{5}{|c|}{ Training group $(n=31)$} & \multicolumn{5}{|c|}{ Control group $(n=29)$} & \multirow{2}{*}{$\begin{array}{l}p \text { Value Between } \\
\text { groups }{ }^{\mathrm{b}} \text { After } \\
\text { intervention }\end{array}$} \\
\hline & \multicolumn{2}{|c|}{ Baseline } & \multicolumn{2}{|c|}{$\begin{array}{l}\text { After } \\
\text { intervention }\end{array}$} & \multirow{2}{*}{$\begin{array}{l}p \text { Value within } \\
\text { group }^{\mathrm{a}} \\
0.006\end{array}$} & \multicolumn{2}{|c|}{ Baseline } & \multicolumn{2}{|c|}{$\begin{array}{l}\text { After } \\
\text { intervention }\end{array}$} & \multirow[t]{2}{*}{$\begin{array}{l}p \text { Value } \\
\text { within group }\end{array}$} & \\
\hline & 0 & $(0-8)$ & 0 & $(0-0)$ & & 0 & $(0-2)$ & 0 & $(0-0.5)$ & & 0.346 \\
\hline Number of voids (times/d) & 8.7 & $(6.7-10.7)$ & 7 & $(6.3-9.0)$ & 0.019 & 9 & $(6.6-10.0)$ & 7.6 & $(6.3-9.7)$ & 0.021 & 0.855 \\
\hline Number of leaks (times/d) & 0 & $(0-0.7)$ & 0 & $(0-0.3)$ & 0.042 & 0 & $(0-0.9)$ & 0 & $(0-0.3)$ & 0.106 & 0.473 \\
\hline
\end{tabular}

a Wilcoxon Sign-Ranks Test.

b Mann-Whitney U-test.

c Number of the control group: 26. 
Table 3

Maximal vaginal squeeze pressure and holding time.

\begin{tabular}{|c|c|c|c|c|c|c|c|c|c|}
\hline & \multicolumn{4}{|c|}{ Training group $(n=31)$} & \multicolumn{4}{|c|}{ Control group $(n=29)$} & \multirow{3}{*}{$\begin{array}{l}\text { Baseline between groups }{ }^{\mathrm{a}} \\
p \text { Value }\end{array}$} \\
\hline & \multicolumn{2}{|c|}{ Baseline } & \multicolumn{2}{|c|}{$\begin{array}{l}\text { After } \\
\text { intervention }\end{array}$} & \multicolumn{2}{|c|}{ Baseline } & \multicolumn{2}{|c|}{$\begin{array}{l}\text { After } \\
\text { intervention }\end{array}$} & \\
\hline & Mean & SD & Mean & SD & Mean & SD & Mean & SD & \\
\hline Maximal vaginal squeeze pressure $\left(\mathrm{cmH}_{2} \mathrm{O}\right)$ & 35.4 & 20.8 & 31.5 & 17.7 & 33.1 & 18.1 & 30.6 & 17.5 & 0.643 \\
\hline Holding time $(s)$ & 8.3 & 5.0 & 11.0 & 5.9 & 7.9 & 4.5 & 11.4 & 5.7 & 0.753 \\
\hline
\end{tabular}

a Independent $t$-test.

quality of life) between groups after 4-months' intervention. Improvement was similar to the home exercise group in a previous study (66\%) (Bo et al., 1990) but higher than untreated controls in others (3\%) (Bo et al., 1999). Improvement in the control group may derive from the behavior modification or self-monitored PFM exercise of participants at home. For ethical reasons, participants in the control group received oral instruction and customary information consisted of introduction for urinary incontinence, PFM exercise, and bladder hygiene. The no-treatment control group in previous studies may not have received this comprehensive information.

Unlike in previous trials of the effects of PFMT (Wilson et al., 1987; Bo et al., 1999; Morkved et al., 2003), our participants showed weaker PFM after intervention with small effect size (0.36). Dumoulin et al. (2004), in an intervention to improve stress incontinence in postpartum women, also found no improvement in PFM maximal strength in intervention groups (PFM and PRM plus abdominal muscles). However, $70 \%$ of those in the intervention groups had no pad leakage (vs. $0 \%$ of controls), and their scores on the pad test, Visual Analog Scale, Urogenital Distress Inventory, and Incontinence Impact Questionnaire significantly improved (all $P<0.002$ ), whereas controls showed no improvements. Although the evaluator encouraged participants to try as hard as possible instead of holding as long as possible in the present trial, there may be sacrifices of strength to get longer holding time during testing with a manometer. We could not exclude the possibility that the improved holding time was a compensation for reduced squeeze intensity. This finding, however, indicates the importance of specificity in muscle strengthening. It has also been argued that increased abdominal pressure from TrA contraction may stretch weak PFM in women with incontinence (Bo et al., 2003). Physical therapists should monitor the co-contraction of TrA and PFM to prevent stretching the PFM with the increased intra-abdominal pressure during this new approach.

There were several limitations in this study. First, to enhance the participation rate, we used self-reported symptoms to define SUI instead of urodynamic studies. Participants were recruited from newspaper advertisements rather than hospital referrals, resulting in participants with a limited scope of symptom severity. Therefore, these results may not extrapolate to a more severely affected population. Moreover, half of the women had $<2 \mathrm{~g}$ leakage during the pad test (13 in the training group and 19 in the control group) at first evaluation, usually objectively defined as a "cure" group (Bo et al., 1999; Dumoulin et al., 2004). This might indicate that the pad test is not a suitable measure for our subclinical participants with mild incontinence. Second, participants were not pure SUI; hey may also suffer from urge incontinence. We could not exclude the effect of uneven distribution of participants with urgency in the two groups (Table 1). The improvement in urgency may affect the subjective report of being cured/improved. Unfortunately, the statistical analysis for the subgroup of SUI and MUI was not suitable due to the small sample size. Also, although many researchers have used the self-reported improvement scale (O'Brien et al., 1991; Lagro-Janssen et al., 1992; Arvonen et al., 2001), it has not been tested psychometrically. The implication of this primary outcome should be carefully assessed. The learning effect of PFM voluntary contraction via vaginal palpation in the first evaluation may be a confounder for this new treatment. Finally, we could not exclude the psychological effect of the imbalance in number of visits between groups.

Table 4

Impacts on quality of life.

\begin{tabular}{|c|c|c|c|c|c|c|c|c|c|c|c|}
\hline & \multicolumn{5}{|c|}{ Training group $(n=31)$} & \multicolumn{5}{|c|}{ Control group $(n=31)$} & \multirow{2}{*}{$\begin{array}{l}p \text { value } \\
\text { Between groups } \\
\text { Post intervention }\end{array}$} \\
\hline & \multicolumn{2}{|c|}{ Baseline } & \multicolumn{2}{|c|}{$\begin{array}{l}\text { After } \\
\text { intervention }\end{array}$} & \multirow[t]{2}{*}{$\begin{array}{l}p \text { value within } \\
\text { group }^{a}\end{array}$} & \multicolumn{2}{|c|}{ Baseline } & \multicolumn{2}{|c|}{$\begin{array}{l}\text { After } \\
\text { intervention }\end{array}$} & \multirow[t]{2}{*}{$\begin{array}{l}p \text { Value Within } \\
\text { group }^{\text {a }}\end{array}$} & \\
\hline \multicolumn{10}{|c|}{ (Values are medians and 25th-75th percentile) } & & \\
\hline Number of worries & 2 & $(1-3)$ & 0 & $(0-1)$ & $<0.001$ & 2 & $(1-3)$ & 0 & $(0-2)$ & 0.002 & 0.163 \\
\hline Number of activities affected & 1 & $(0-2)$ & 0 & $(0-0)$ & $<0.001$ & 1 & $(0-2)$ & 0 & $(0-2)$ & 0.104 & 0.024 \\
\hline \multicolumn{12}{|c|}{ (Values are numbers and percentile) } \\
\hline Never & 11 & $(35.5)$ & 23 & $(74.2)$ & 0.001 & 12 & $(38.7)$ & 16 & $(51.6)$ & 0.002 & 0.060 \\
\hline Sometimes & 15 & $(48.4)$ & 8 & $(25.8)$ & & 11 & $(35.5)$ & 14 & $(45.2)$ & & \\
\hline Often & 5 & $(16.1)$ & 0 & $(0.0)$ & & 8 & $(25.8)$ & 1 & $(3.2)$ & & \\
\hline Always & 0 & $(0.0)$ & 0 & $(0.0)$ & & 0 & $(0.0)$ & 0 & $(0.0)$ & & \\
\hline \multicolumn{12}{|c|}{ Avoiding activity due to needing a toilet } \\
\hline Never & 9 & $(29.0)$ & 24 & $(77.4)$ & $<0.001$ & 12 & $(38.7)$ & 15 & $(48.4)$ & 0.085 & 0.013 \\
\hline Sometimes & 19 & $(61.3)$ & 7 & $(22.6)$ & & 12 & $(38.7)$ & 13 & (41.9) & & \\
\hline Often & 2 & $(6.5)$ & 0 & $(0.0)$ & & 6 & (19.4) & 3 & $(9.7)$ & & \\
\hline Always & 1 & $(3.2)$ & 0 & $(0.0)$ & & 1 & $(3.2)$ & 0 & $(0.0)$ & & \\
\hline
\end{tabular}

a Wilcoxon Sign-ranks Test.

b Mann-Whitney $U$-Test. 
Table 5

Self-reported improvement in overall incontinence and stress incontinence aspect after intervention.

\begin{tabular}{|c|c|c|c|c|}
\hline & \multicolumn{2}{|c|}{$\begin{array}{l}\text { Training group } \\
(n=31)\end{array}$} & \multicolumn{2}{|c|}{$\begin{array}{l}\text { Control group } \\
(n=33)\end{array}$} \\
\hline & $n$ & $\%$ & $n$ & $\%$ \\
\hline Cured & 5 & 16.1 & 1 & 3.0 \\
\hline Improved & 25 & 80.6 & 21 & 63.6 \\
\hline Unchanged & 1 & 3.2 & 10 & 30.3 \\
\hline Worse & 0 & 0.0 & 1 & 3.0 \\
\hline
\end{tabular}

This was the first randomized controlled trial of the effect of retraining diaphragmatic, deep abdominal and PFM coordinated function. Results suggested that this approach may be appropriate for women unwilling or unable to participate in specific PFM strengthening. Further research is urgently required, but this is an exciting first step. However, clinical implications should be carefully interpreted due to the limitations mentioned. Further studies will need to differentiate the treatment effect for different populations by incontinence type, severity, age or other important factors. Both mechanism and long-term effect also must be delineated. Cost effectiveness analysis of this new approach compared to health education, group exercises or individual PFM training are also needed.

\section{Conclusion}

A 4-month period intervention by retraining diaphragmatic, deep abdominal and PFM coordinated function could improve symptoms and quality of life in women with SUI or MUI. This new approach shows promise as an alternative for women with incontinence, particularly those who cannot accept vaginal palpation.

\section{Acknowledgements}

To ensure correct execution, the training physical therapist met and learned the techniques and discussed all the related issues with the original designer before this trial. The authors thank physical therapist Ruth Sapsford for her teaching of the specific rehabilitation techniques. We also thank the participants and the National Science Council of the Republic of China for financial support under grant no. NSC95-2314-B002-226-MY2, which made this study possible.

\section{Appendix}

Detailed exercise regimen and estimated progression in the present trial (Sapsford, 2004).

\begin{tabular}{|c|c|}
\hline Stage & Exercise regimen \\
\hline I. Diaphragmatic breathing (wk1 4) & $\begin{array}{l}\text { Position: lying, sitting, standing } \\
\text { Home exercise: } 30 \text { repetitions } \times 3 \text { sets/day }\end{array}$ \\
\hline II-1. Tonic TrA and PFM activation (wk2 5) & $\begin{array}{l}\text { Prerequisite: correct diaphragmatic breathing } \\
\text { Position: standing } \\
\text { Instruction: Try to lift up your lower abdomen cranially with normal diaphragmatic breathing. } \\
\text { The spinal and pelvic motion was prohibited. } \\
\text { Feedback: in front of a mirror to see the lower abdominal movement; tactile input medial to ASIS by } \\
\text { both therapist and participant; participant's subjective feeling of tensioning response around periurethral, } \\
\text { perivaginal, and perianal region. } \\
\text { Home exercise: } 5 \text { repetitions } \times 5 \text { sets/day, holding the contraction as long as possible, and gradually increase } \\
\text { the holding time to } 40 \mathrm{~s} \text { up. }\end{array}$ \\
\hline II-2. Tonic activation with ADL, walking (wk4 7) & $\begin{array}{l}\text { Prerequisite: the participant can hold the tonic TrA/PFM co-contraction with suprapubic firmness easily for } 40 \mathrm{~s} \\
\text { Position: upright position } \\
\text { Instruction: incorporate the co-contraction into daily activities in standing and walking } \\
\text { Feedback: participant's subjective feeling of tensioning response around periurethral, } \\
\text { perivaginal, and perianal region. } \\
\text { Home exercise: } 6 \text { tasks } \times 2 \text { sets/day, target at holding the contraction with walking for more than } 15 \mathrm{~s}\end{array}$ \\
\hline III. Muscle strengthening (wk6 16) & $\begin{array}{l}\text { Prerequisite: tonic TrA/PFM co-contraction can be maintained easily during walking for more than } 15 \mathrm{~s} \\
\text { Position: standing } \\
\text { Instruction: start with the gentle lower abdominal activation used in the previous stage, then keep } \\
\text { pulling the lower abdomen in towards the spine and pulling up the periurethral PFM as far as possible. } \\
\text { Spinal movement was avoided to minimize the activity of rectus abdominal muscle. } \\
\text { Feedback: tactile input medial to ASIS by both therapist and participant } \\
\text { Home exercise: hold the strong contraction for } 5 \mathrm{~s}, 6 \text { repetition } \times 2 \text { sets/day }\end{array}$ \\
\hline IV. Functional expiratory patterns (wk8 16) & $\begin{array}{l}\text { (Nose blowing) (wk8 9) } \\
\text { Position: begin with sitting upright without support, progressed to standing and slumped supported sitting } \\
\text { Instruction: begin with the diaphragmatic breathing for } 3-5 \text { times, make sure the anterior-posterior diameter } \\
\text { of abdomen increased during inspiration. After the last full inspiration, incorporates a strong cognitive } \\
\text { abdominal pulling in contraction as the nose blowing takes place } \\
\text { Feedback: in front of a mirror to see the chest and abdomen motion; hand palpation at lower abdomen; } \\
\text { the abdominal wall should be pulled in and the lower rib cage should be widened laterally; } \\
\text { participant's subjective feeling of tensioning response around periurethral, perivaginal, and perianal region. } \\
\text { Home exercise: } 5 \text { repetitions } \times 2 \text { sets/day } \\
\text { (Coughing) (wk10 16) } \\
\text { Note: require stronger and faster abdominal muscle contraction } \\
\text { (Laughing) (wk10 16) } \\
\text { Note: require the ability to repeat and sustain the contraction of abdominal muscles and PFM } \\
\text { (Sneezing) (wk12 16) } \\
\text { Note: require the greatest muscle power and correct timing }\end{array}$ \\
\hline V. Impact activities (wk10 16) & $\begin{array}{l}\text { Prerequisite: tonic } \mathrm{TrA} / \mathrm{PFM} \text { co-contraction can be maintained easily during walking for more than } 15 \mathrm{~s} \\
\text { Instruction: incorporate the tonic TrA/PFM contraction into impact activities, such as running, jumping, dancing } \\
\text { Home exercise: according to participant's activity schedule }\end{array}$ \\
\hline
\end{tabular}




\section{References}

Abrams P, Cardozo L, Fall M, Griffiths D, Rosier P, Ulmsten U, et al. The standardisation of terminology of lower urinary tract function: report from the standardisation sub-committee of the International Continence Society. Neurourology and Urodynamics 2002;21(2):167-78.

Arvonen T, Fianu-Jonasson A, Tyni-Lenne R. Effectiveness of two conservative modes of physical therapy in women with urinary stress incontinence. Neurourology and Urodynamics 2001;20(5):591-9.

Black N, Griffiths J, Pope C. Development of a symptom severity index and a symptom impact index for stress incontinence in women. Neurourology and Urodynamics 1996;15(6):630-40.

Bo K, Hagen RH, Kvarstein B, Jorgensen J, Larsen S. Pelvic floor muscle exercise for the treatment of female stress urinary incontinence: III. Effects of two different degrees of pelvic floor muscle exercises. Neurourology and Urodynamics 1990;9:489-502.

Bo K, Sherburn M, Allen T. Transabdominal ultrasound measurement of pelvic floor muscle activity when activated directly or via a transversus abdominis muscle contraction. Neurourology and Urodynamics 2003;22(6):582-8.

Bo K, Talseth T, Holme I. Single blind, randomised controlled trial of pelvic floor exercises, electrical stimulation, vaginal cones, and no treatment in management of genuine stress incontinence in women. British Medical Journal 1999;318(7182):487-93.

Chen GD, Lin TL, Hu SW, Chen YC, Lin LY. Prevalence and correlation of urinary incontinence and overactive bladder in Taiwanese women. Neurourology and Urodynamics 2003;22(2):109-17.

Chen HY, Chang WC, Lin WC, Yeh LS, Hsu TY, Tsai HD, et al. Efficacy of pelvic floor rehabilitation for treatment of genuine stress incontinence. Journal of the Formosan Medical Association 1999;98(4):271-6.

Dumoulin C, Lemieux MC, Bourbonnais D, Gravel D, Bravo G, Morin M. Physiotherapy for persistent postnatal stress urinary incontinence: a randomized controlled trial. Obstetrics \& Gynecology 2004;104(3):504-10.

Frawley HC, Galea MP, Phillips BA, Sherburn M, Bo K. Reliability of pelvic floor muscle strength assessment using different test positions and tools. Neurourology and Urodynamics 2006;25(3):236-42.

Groutz A, Blaivas JG, Chaikin DC, Resnick NM, Engleman K, Anzalone D, et al. Noninvasive outcome measures of urinary incontinence and lower urinary tract symptoms: a multicenter study of micturition diary and pad tests. Journal of Urology 2000;164(3 Pt 1):698-701.

Hay-Smith EJ, Dumoulin C. Pelvic floor muscle training versus no treatment, or inactive control treatments, for urinary incontinence in women. Cochrane Database of Systematic Reviews 2006;(1):CD005654.

Howard D, Miller JM, Delancey JO, Ashton-Miller JA. Differential effects of cough, valsalva, and continence status on vesical neck movement. Obstetrics \& Gynecology 2000;95(4):535-40.
Kegel AH. Progressive resistance exercise in the functional restoration of the perineal muscles. American Journal of Obstetrics and Gynecology 1948;56(2): 238-48.

Lagro-Janssen AL, Debruyne FM, Smits AJ, van Weel C. The effects of treatment of urinary incontinence in general practice. Family Practice 1992;9(3):284-9.

Madill SJ, McLean L. Relationship between abdominal and pelvic floor muscle activation and intravaginal pressure during pelvic floor muscle contractions in healthy continent women. Neurourology and Urodynamics 2006;25(7): 722-30.

Morin M, Bourbonnais D, Gravel D, Dumoulin C, Lemieux MC. Pelvic floor muscle function in continent and stress urinary incontinent women using dynamometric measurements. Neurourology and Urodynamics 2004;23(7):668-74.

Morkved S, Bo K, Schei B, Salvesen KA. Pelvic floor muscle training during pregnancy to prevent urinary incontinence: a single-blind randomized controlled trial. Obstetrics \& Gynecology 2003;101(2):313-9.

Morkved S, Salvesen KA, Bo K, Eik-Nes S. Pelvic floor muscle strength and thickness in continent and incontinent nulliparous pregnant women. International Urogynecology Journal and Pelvic Floor Dysfunction 2004;15(6):384-9.

Neumann P, Gill V. Pelvic floor and abdominal muscle interaction: EMG activity and intra-abdominal pressure. International Urogynecology Journal and Pelvic Floor Dysfunction 2002;13(2):125-32.

O’Brien J, Austin M, Sethi P, O’Boyle P. Urinary incontinence: prevalence, need for treatment, and effectiveness of intervention by nurse. British Medical Journal 1991;303(6813):1308-12.

Rohr G, Christensen K, Ulstrup K, Kragstrup J. Reproducibility and validity of simple questions to identify urinary incontinence in elderly women. Acta Obstetricia et Gynecologica Scandinavica 2004;83(10):969-72.

Sand PK. The evaluation of the incontinence female. Current Problems in Obstetrics, Gynecology \& Fertility 1992;15:107-51.

Sapsford R. Rehabilitation of pelvic floor muscles utilizing trunk stabilization. Manual Therapy 2004;9(1):3-12.

Sapsford RR, Hodges PW. Contraction of the pelvic floor muscles during abdominal maneuvers. Archives of Physical Medicine and Rehabilitation 2001;82(8): 1081-8.

Sapsford RR, Hodges PW, Richardson CA, Cooper DH, Markwell SJ, Jull GA. Co-activation of the abdominal and pelvic floor muscles during voluntary exercises. Neurourology and Urodynamics 2001;20(1):31-42.

Thompson JA, O'Sullivan PB, Briffa NK, Neumann P. Altered muscle activation patterns in symptomatic women during pelvic floor muscle contraction and valsalva manouevre. Neurourology and Urodynamics 2006;25(3):268-76.

Wilson PD, Al Samarrai T, Deakin M, Kolbe E, Brown AD. An objective assessment of physiotherapy for female genuine stress incontinence. British Journal of Obstetrics and Gynaecology 1987;94(6):575-82.

Wu WY, Sheu BC, Lin HH. Comparison of 20-min pad test versus 1-h pad test in women with stress urinary incontinence. Urology 2006;68(4):764-8. 